\title{
KONSISTENSI DAN KUAT TEKAN MORTAR YANG MENGGUNAKAN AIR LAUT SEBAGAI MIXING WATER $(\mathbf{0 3 8 M})$
}

\author{
Erniati $^{1 *}$, M. Wihardi Tjaronge ${ }^{2}$, Rudy Djamaluddin ${ }^{3}$ dan Victor Sampebulu $^{4}$ \\ ${ }^{1}$ Mahasiswa Program Doktor, Teknik Sipil, UNHAS, Jl. Perintis Kemerdekaan Km.10 Tamalanrea Makassar \\ *Program Studi Teknik Sipil, Fakultas Teknik, Universitas Fajar, Jl. Prof. Dr. H. Abd Basalamah Makassar \\ Email:erni_nurzaman@yahoo.com \\ ${ }^{2,3}$ Jurusan Teknik Sipil, Universitas Hasanuddin, Jl. Perintis Kemerdekaan Km.10 Tamalanrea Makassar \\ Email': tjaronge@yahoo.co.jp,Email ${ }^{3}:$ rudy0011@yahoo.com \\ ${ }^{4}$ Jurusan Tenik Arsitektur, Universitas Hasanuddin, Jl. Perintis Kemerdekaan Km.10 Tamalanrea Makassar \\ Email': vicsam_ars@yahoo.com
}

\begin{abstract}
ABSTRAK
Air laut merupakan salah satu sumber daya alam yang sangat melimpah. Menurut PBB pada tahun 2050, lebih dari setengah dari penduduk dunia tidak akan bisa mendapatkan air minum yang cukup, sehingga penelitian tentang penghematan air tawar serius diperlukan. Penggunaan air laut, yang persentase adalah $97 \%$ dari total air di bumi, mutlak diperlukan. Makalah ini akan ditinjau pengaruh air laut terhadap konsistensi dan kuat tekan mortar yang menggunakan air laut sebagai air pencampuran (Mixing Water). Pengujian konsistensi, waktu ikat dan kuat tekan mortar sesuai standar Standar Nasional Indonesia (SNI). Variabel yang digunakan adalah umur dan jenis air pencampuran yang digunakan adalah aquades dan air laut. Hasil penelitian yang diperoleh konsistensi mortar yang menggunakan aquades lebih kecil dibandingkan dengan konsistensi air laut. Waktu ikat awal dan akhir lebih cepat menggunakan air laut dan masih memenuhi standar waktu ikat. Kuat tekan mortar yang menggunakan aquades dan air laut pada umur 3, 7 dan 28 hari memenuhi standar SNI 15-7064-2004. Kuat tekan air laut pada umur 3 dan 7 dan 28 lebih tinggi dibandingkan aquades. Perbedaan kuat tekan mortar antara aquades dan air laut pada umur 3,7,dan 28 hari berturut turut $21,11 \%, 8,2 \%$, dan $3,16 \%$.
\end{abstract}

Kata kunci: mortar, air laut, konsistensi, waktu ikat, kuat tekan.

\section{PENDAHULUAN}

Pada tahun 2000, dunia berpopulasi 6,2 miliar. PBB memperkirakan bahwa pada tahun 2050, dunia akan mendapatkan tambahan penduduk sekitar 3,5 miliar dengan pertumbuhan terbesar ada di negara-negara berkembang yang telah mengalami krisis air (Wikipedia, 2013). Technical committee JCI menyatakanpada tahun 2050, menurut PBB, lebih dari setengah dari penduduk dunia tidak akan bisa mendapatkan air minum yang cukup, sehingga penghematan air tawar serius diperlukan sehingga penggunaan air laut, yang persentase adalah $97 \%$ dari total air di bumi, mutlak diperlukan. Pembangunan infrastruktur semakin meningkat yang seiring dengan kebutuhan air bersih semakin banyak. Dalam industri beton, beberapa miliar ton air yang digunakan di bumi sebagai air pencampuran, air perawatan (curing) dan air pembersih setiap tahun, dimana penggunaan air laut terhalangi (JCI-TC-121A).

Indonesia merupakan negara kepulauan sehingga banyak wilayah yang kualitas sumber air tidak memenuhi syarat sebagi air minum. Pembangunan konstruksi beton pada daerah yang kemungkinan kuantitas air bersih/tawar sangat minimal/tidak ada, maka air laut tidak dapat dihindari dalam pencampuran beton dan pemeliharan. Menurut otsuki, dkk (2011;2012), bahwa dalam waktu dekat, air bersih akan sangat sulit untuk didapatkan dan terbatas. Juga mengungkapkan bahwa masa sekarang, ada beberapa daerah di mana air laut atau pasir yang mengandung klorida digunakan sebagai air/bahan pencampur dengan atau tanpa intensi.

Dalam siklus kehidupan ini, dunia teknik sipil terutama pada negara maju telah memikirkan tentang tantangan kedepan akan berkurangnya potensi air bersih (air tawar) yang dapat digunakan sebagai bahan pencampuran beton. Jika penggunaan air laut pada pembangunan infrastruktur dan industri beton diijinkan, air segar akan banyak banyak tersimpan. 
Beton merupakan campuran dari bahan penyusunnya yang terdiri dari semen, agregat kasar, agregat halus, air dengan atau tanpa bahan tambah. Beton yang berkualitas jika beton mempunyai karakteristik mekanik dan ketahanan yang baik. Mortar merupakan campuran yang terdiri dari semen dan air dan agregat halus (pasir).

Salah satu bahan penyusun adukan beton/mortar adalah air yang berfungsi untuk memicu proses kimiawi semen sebagai bahan perekat/pengikat agregat dan melumasi agregat agar mudah dikerjakan. Padahal umumya air yang digunakan dalam pembuatan beton/mortar adalah air yang dapat diminum/air tawar. Kuantitas dan kualitas air akan mempengaruhi kekuatan dan ketahanan.

\title{
2. TINJAUAN PUSTAKA
}

\section{Mortar}

Menurut SNI 15-2049-2004 mortar merupakan suatu campuran yang terdiri dari semen, agregat halus dan air baik dalam keadaan dikeraskan ataupun tidak dikeraskan Kekuatan tekan mortar semen Portland adalah gaya maksimum per satuan luas yang bekerja ada benda uji mortar semen Portland berbentuk kubus dengan ukuran tertentu serta berumur tertentu.

\begin{abstract}
Air laut
Rompas, R.M. dkk (2009), air yang ada diperairan laut tidak berbentuk air murni namun terasosiasi dengan beberapa garam, para ahli sepakat ukuran garam-garam yang terlarut di dalam air laut menggunakan satuan salinitas (salinity). Salinitas air laut umumnya berkisar antara 33-37\%o tergantung pada kondisi wilayahnya, yakni yang banyak curah hujan, muara sungai, limpasan es dan salju dan daerah yang setengah tertutup (semi-enclosed). Khusus dilaut merah sering terjadi proses evaporasi yang sangat cepat, kadar salinitasnya dapat mencapai 40\%. Kandungan utama air laut didominasi oleh klorin yang mencapai 55\% dari total garam-garam yang terlarut, kemudian kedua yang terbanyak adalah natrium mencapai $30,61 \%$.
\end{abstract}

Rompas, R.M. dkk (2009), perairan laut merupakan wilayah terbesar yang mendiami bumi kita yaitu mencapai 70,8\%. Wikipedia (2013), air di laut merupakan campuran dari 96,5\% air murni dan 3,5\% material lainnya seperti garam-garaman, gas-gas terlarut, bahan-bahan organik dan partikel-partikel tak terlarut. Air laut memiliki kadar garam garam rata-rata sekitar $35.000 \mathrm{ppm}$ (3,5\% atau $35 \mathrm{~g} / \mathrm{liter})$. Kandungan kimia utama dari air laut adalah klorida $(\mathrm{Cl})$, natrium $(\mathrm{Na})$, magnesium $(\mathrm{Mg})$, Sulfat $\left(\mathrm{SO}_{4}\right)$. Nilai $\mathrm{pH}$ air laut bervariasi antara 7,5 - 8,4. Berat jenis air laut permukaan berkisar antara 1.020 - 1.029. Dari semua sumber air yang ada, air asin yang berasal dari laut adalah air dengan jumlah terbanyak yang mencapai sekitar $97 \%$ dari jumlah total air yang ada di bumi, sedangkan untuk jumlah total air tawar hanya sekitar 3\%. Dimana 2\% air tawar yang ada tersedia dalam bentuk es di glasier dan es kutub utara/selatan, sedangkan air tawar sisanya yang $1 \%$ paling banyak berada di dalam tanah dan hanya sedikit yang merupakan air permukaan.

\section{Hidrasi semen}

Hidrasi semen adalah reaksi antara partikel semen dan air, termasuk proses kimia dan fisika. Sifat-sifat beton segar, seperti ikatan (seetting) dan pengerasan, adalah hasil langsung dari hidrasi. Sifat-sifat beton keras juga dipengaruhi oleh proses hidrasi. Oleh karena itu, untuk memahami sifat dan perilaku semen dan beton, beberapa pengetahuan tentang kimia hidrasi diperlukan.

Hidrasi semen Portland melibatkan unsur-unsur semen yaitu reaksi kalsium silikat anhidrat dan aluminat dengan air untuk membentuk fase terhidrasi. Hidrasi semen sangat kompleks sehingga reaksi dari masing-masing unsur semen dalam bentuk silikat $\left(\mathrm{C}_{3} \mathrm{~S}\right.$ dan $\left.\mathrm{C}_{2} \mathrm{~S}\right)$ dan aluminat $\left(\mathrm{C}_{3} \mathrm{~A}\right.$ dan $\left.\mathrm{C}_{4} \mathrm{AF}\right)$ dianalisa masing-masing secara tunggal.

\section{Hidrasi silikat}

Kedua silikat $\mathrm{C}_{3} \mathrm{~S}$ dan $\mathrm{C}_{2} \mathrm{~S}$ bereaksi dengan air untuk menghasilkan hidrat kalsium silikat amorf yang dikenal sebagai gel C-S-H (gel tobermorite) yang merupakan perekat utama yang mengikat partikel pasir dan agregat bersama-sama dalam beton. $\mathrm{C}_{3} \mathrm{~S}$ jauh lebih reaktif dari $\mathrm{C}_{2} \mathrm{~S}$ dan pada kondisi suhu standar, sekitar $20^{\circ} \mathrm{C}$, sekitar separuh dari $\mathrm{C}_{3} \mathrm{~S}$ dalam semen akan terhidrasi dalam 3 hari dan $80 \%$ dalam 28 hari. Sebaliknya, hidrasi $\mathrm{C}_{2} \mathrm{~S}$ biasanya tidak berlangsung normal hingga 14 hari. Kelebihan $\mathrm{Ca}$ diendapkan sebagai kristal kalsium hidroksida, $\mathrm{Ca}(\mathrm{OH})_{2}$ atau portlandite $(\mathrm{CH})$. Hidrasi $\mathrm{C}_{2} \mathrm{~S}$ juga menghasilkan beberapa formasi $\mathrm{CH}$. 
$\mathrm{Ca}(\mathrm{OH})_{2}$ yang terbebaskan oleh hidrolisis kalsium silikat membentuk pelat-pelat tipis heksagonal, dengan jarak puluhan micrometer antara pelat, tetapi kemudian bergabung menjadi deposit besar. Reaksi hidrasi dapat dilihat pada Persamaan 1 dan 2.

$$
\begin{aligned}
& \mathrm{C}_{3} \mathrm{~S}+4.3 \mathrm{H} \rightarrow \mathrm{C} 1.7 \mathrm{SH}_{3}+1.3 \mathrm{CH} \\
& \mathrm{C}_{2} \mathrm{~S}+3.3 \mathrm{H} \rightarrow \mathrm{C} 1.7 \mathrm{SH}_{3}+0.3 \mathrm{CH}
\end{aligned}
$$

Atau dengan menggunakan persamaan stoikhiometri dapat juga disederhanakan seperti pada Persamaan 3 dan 4 (Neville, A.M and Brooks, J.J , 2010); Zongjin Li, 2011).

$$
\begin{aligned}
& 2 \mathrm{C}_{3} \mathrm{~S}+6 \mathrm{H} \rightarrow \mathrm{C}_{3} \mathrm{~S} 2 \mathrm{H}_{3}+3 \mathrm{Ca}(\mathrm{OH})_{2} \\
& 2 \mathrm{C}_{2} \mathrm{~S}+4 \mathrm{H} \rightarrow \mathrm{C}_{3} \mathrm{~S} 2 \mathrm{H}_{3}+\mathrm{Ca}(\mathrm{OH})_{2}
\end{aligned}
$$

\section{Hidrasi alumina}

Komposisi aluminat fase dalam klinker dan dalam hidrasi semen sangat dipengaruhi oleh kuantitas yang besar dari reaksi silikat dan juga oleh adanya basa. Dengan tidak adanya larutan kalsium sulfat, C3A bereaksi dengan cepat untuk membentuk fase $\mathrm{C}_{2} \mathrm{AH} 8$ dan $\mathrm{C}_{4} \mathrm{AH}_{19}$, yang kemudian mengkonversi ke $\mathrm{C}_{3} \mathrm{AH}_{6}$. lihat pada Persamaan 5, 6 dan 7 (Zongjin Li, 2011).

$$
\begin{aligned}
& 2 \mathrm{C}_{3} \mathrm{~A}+27 \mathrm{H} \rightarrow \mathrm{C}_{4} \mathrm{AH}_{19}+\mathrm{C}_{2} \mathrm{AH}_{8} \\
& 2 \mathrm{C}_{3} \mathrm{~A}+21 \mathrm{H} \rightarrow \mathrm{C}_{4} \mathrm{AH}_{13}+\mathrm{C}_{2} \mathrm{AH}_{8} \\
& \mathrm{C}_{4} \mathrm{AH}_{13}+\mathrm{C}_{2} \mathrm{AH}_{8} \rightarrow 2 \mathrm{C}_{3} \mathrm{AH}_{6}+9 \mathrm{H} .
\end{aligned}
$$

Reaksi ini adalah cepat dan sangat eksotermis (flash set) dan tidak dapat dikendalikan secara kinetik. Untuk mengendalikan hidrasi $\mathrm{C}_{3} \mathrm{~A}$ agar tidak terjadi flash set, maka pada saat pembuatan klinker ditambahkan gypsum. Jika gypsum yang telah ditumbuk halus $\left(\mathrm{CaSO}_{4} \cdot 2 \mathrm{H}_{2} \mathrm{O}\right)$ atau dalam bentuk hemihydrate $\left(\mathrm{CaSO}_{4} \cdot 0.5 \mathrm{H}_{2} \mathrm{O}\right)$ dicampur dengan $\mathrm{C}_{3} \mathrm{~A}$ sebelum pencampuran dengan air maka reaksi awal dapat dikendalikan oleh ettringite $\left(\mathrm{C}_{6} \mathrm{AS}_{3} \mathrm{H}_{32}\right)$, suatu lapisan pelindung yang terbentuk pada permukaan kristal $\mathrm{C}_{3} \mathrm{~A}$. Reaksi dapat diringkas sebagai:

Dimana $\hat{\mathrm{S}}$ adalah $\mathrm{SO}_{3}$ dan $\mathrm{H}$ menunjukkan $\mathrm{H}_{2} \mathrm{O}$.

$$
\begin{aligned}
& \mathrm{C}_{3} \mathrm{~A}+3 \mathrm{CS}^{\mathrm{S}} \mathrm{H}_{2}+26 \mathrm{H} \rightarrow \mathrm{C} \mathrm{AS}_{3} \mathrm{H}_{32} \text { (ettringite), atau } \\
& \mathrm{C}_{3} \mathrm{~A}+3 \mathrm{C}+3 \hat{\mathrm{S}}+32 \mathrm{H} \rightarrow \mathrm{C}_{3} \mathrm{ACS}_{32} \mathrm{H}_{32}
\end{aligned}
$$

Ettringite biasa juga disebut Aft-fase. Ketika sulfat yang tersedia telah habis, ettringite bereaksi dengan C3A untuk membentuk fase dengan kandungan $\mathrm{SO}_{3}$ rendah dikenal sebagai monosulfate. Reaksi dapat diringkas seperti pada Persamaan 10.

$$
2 \mathrm{C}_{3} \mathrm{~A}+\mathrm{C}_{6} \mathrm{AS}_{3} \mathrm{H}_{32}+4 \mathrm{H} \rightarrow 3 \mathrm{C}_{4} \mathrm{AS} \mathrm{S}_{12}
$$

Dan bersama dengan $\mathrm{CH}$ dari hidrasi $\mathrm{C}_{3} \mathrm{~S}$ dan $\mathrm{C}_{2} \mathrm{~S}$ terjadi reaksi seperti pada Persamaan 11.

$$
\mathrm{C}_{3} \mathrm{~A}+\mathrm{CH}+12 \mathrm{H} \rightarrow \mathrm{C}_{4} \mathrm{AH}_{13}
$$

\section{METODE DAN BAHAN PENELITIAN}

\section{Metode}

Metode yang digunakan adalah metode eksperimen dengan mengacu kepada SNI 15-2049-2004. Pengujian yang dilakukan konsistensi, waktu ikat dan kuat tekan mortar semen PCC. Variabel yang digunakan adalah jenis air pencampuran yang digunakan adalah aquades dan air laut.

\section{Bahan}

Penelitian ini menggunakan bahan semen Portland Komposit (Portland Cement composite/PCC) merek PT. Tonasa, pasir otawa, air laut (sekitar tanjung bunga) dan aquades.

\section{Konsistensi dan waktu ikat}

Pengujian konsistensi menggunakan alat vicat yang bertujuan untuk menentukan jumlah air yang dibutuhkan pada pasta semen. Pengujian ini dilakukan dengan menggunakan aquades dan air laut. Waktu ikat dilakukan jika konsistensi telah memenuhi syarat.

\section{Pengujian kuat tekan mortar}

Benda uji menggunakan cetakan kubus berukuran sisi $50 \mathrm{~mm}$. Benda uji dibuat masing-masing 9 benda uji. Yang diperoleh dengan 2 kali pencampuran (mixing) yakni dengan mengunakan mixing water aquades dan air laut. Benda uji dirawat dengan sesuai jenis air pencampuran. Pengujian kuat tekan dilakukan pada umur 3,7, dan 28 hari. 


\section{HASIL DAN PEMBAHASAN}

\section{Hasil pengujian konsistensi dan waktu ikat}

Hasil pengujian konsistensi dan waktu ikat semen PCC diperlihatkan pada Gambar 1 dan 2. Terlihat bahwa Konsistensi air laut lebih tinggi dibandingkan dengan menggunakan aquades yang sebagai standar yakni $24,15 \%$ dan 24,46\%. Perbedaan konsistensi air laut sekitar 1,3\% dari konsistensi semen yang menggunakan aquades. Konsistensi normal berkisar antara $22-28 \%$, jadi konsistensi pasta semen yang menggunakan air laut masih memenuhi standar.

Waktu ikat awal dan akhir terlihat bahwa pasta yang menggunakan air laut lebih cepat dibandingkan dengan aquades berturut sekitar 17 menit dan 20 menit. Waktu ikat awal pada semen berkisar antara 60 - 120 menit. Dengan demikian waktu ikat awal dan akhir masih memenuhi standar.

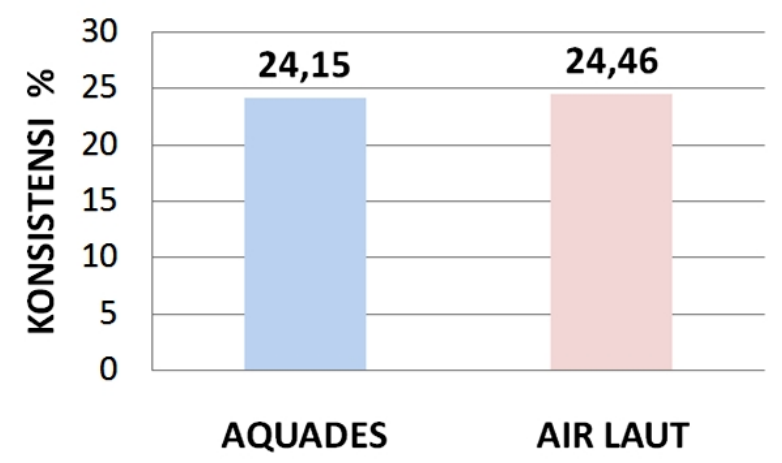

Gambar 1. Konsistensi pasta semen

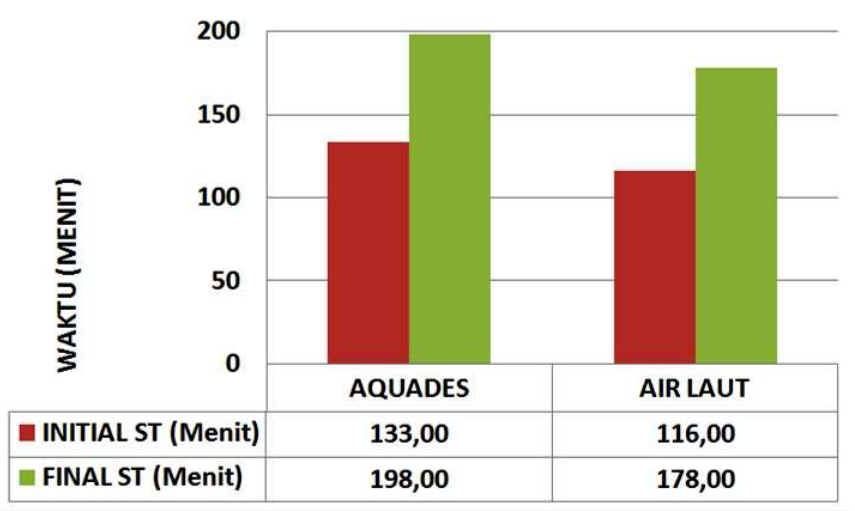

Gambar 2. Waktu ikat pasta semen

\section{Hasil pengujian kuat tekan mortar}

Pengaruh air laut terhadap kuat tekan mortar diperlihatkan pada Tabel 1. Kuat tekan mortar yang menggunakan baik aquades dan air laut semakin tinggi seiring dengan umur mortar seperti yang diperlihatkan pada Gambar 3. Dari Grafik memperlihatkan bahwa air laut tidak mempengaruhi proses hidrasi pada umur dini mortar.

Tabel 1. Kuat Tekan Mortar

\begin{tabular}{cccc}
\hline \multirow{2}{*}{ Umur (Hari) } & \multicolumn{2}{c}{ Kuat Tekan (MPa) } & $\begin{array}{c}\text { Perbedaan kuat } \\
\text { tekan (\%) }\end{array}$ \\
\cline { 2 - 3 } & Aquades & Air Laut & 21,11 \\
\hline 3 & 20,43 & 25,90 & 7,82 \\
\hline 7 & 27,10 & 29,40 & 3,16 \\
\hline 28 & 31,73 & 32,77 & \\
\hline
\end{tabular}




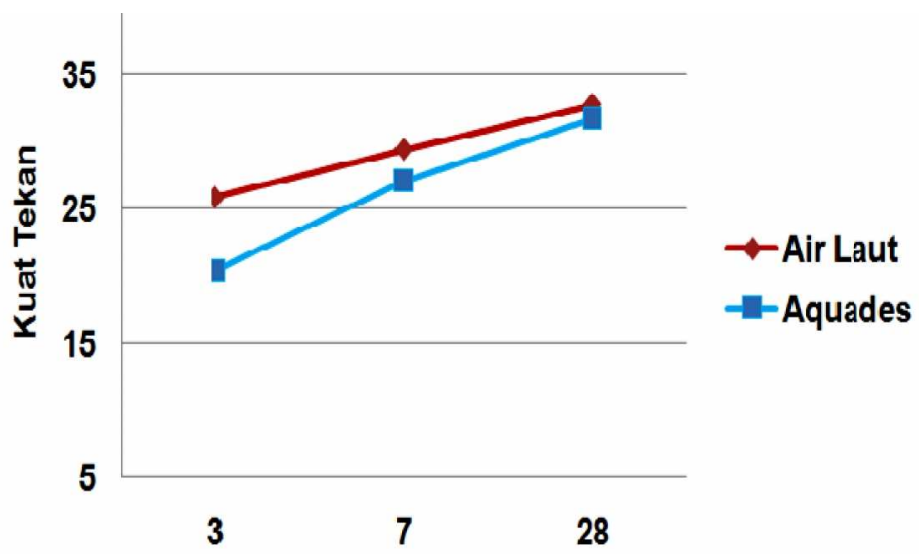

Gambar 3. Perbandingan kuat tekan mortar yang menggunakan aquades dan air laut.

Kuat tekan akibat air laut lebih tinggi sekitar $21 \%$ pada umur 3 hari, dan pada umur selanjutnya perbedaan kuat tekan pada umur dan 28 hari semakin menurun yakni berturut-turut sebesar 7,82\% dan 3,16\%. Kuat tekan mortar yang menggunakan air laut lebih tinggi, karena kemungkinan akibat kehadiran klorida yang ada pada air laut, yang sebagaimana menurut Aburawy, MM dan Swamy, R.N (2008), kehadiran klorida mempercepat perkembangan kekuatan usia dini pada beton dengan terak sampai sekitar 7-14 hari. Disamping itu penambahan natrium klorida pada beton segar akan membentuk kristal garam friedel (friedel's salt: $3 \mathrm{CaO} . \mathrm{Al}_{2} \mathrm{O}_{3} \cdot \mathrm{CaCl}_{2} \cdot 10 \mathrm{H}_{2} \mathrm{O}$ ) yang dapat meningkatkan $\mathrm{pH}$ lebih tinggi, dan alkalinitas meningkat sehingga akan mengaktifkan hidrasi semen serta memberikan struktur pasta lebih padat dengan pori-pori yang lebih kecil (Pruckner, F. dan Gjorv, O.E, 2003).

Penurunan perbedaan kuat tekan antara mortar yang menggunakan aquades dan air laut dapat dilihat pada Gambar 4.

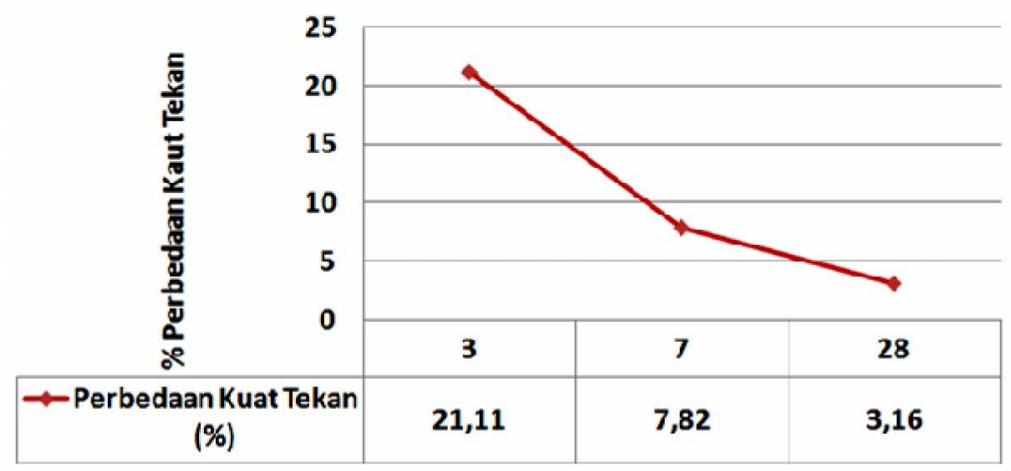

Gambar 4. Persentase perbedaan kuat tekan mortar yang menggunakan aquades dan air laut

\section{KESIMPULAN}

1. Penggunaan air laut berpengaruh pada konsistensi dan waktu ikat semen dan kuat tekan mortar

2. Perbedaan konsistensi semen yang menggunakan aquades dan air laut sebesar $1,3 \%$

3. Waktu ikat dan akhir semen PCC yang menggunakan air laut lebih cepat dibandingkan dengan yang menggunakan aquades.

4. Perbedaan kuat tekan tekan mortar yang menggunakan air laut dengan kuat tekan mortar yang menggunakan aquades pada usia dini umur 3,7, dan 28 sebesar berturut $21,11 \%, 82 \%$ dan 3,16 .

5. Air laut menaikkan kuat tekan mortar pada usia dini, karena kemungkinan adanya kandungan klorida pad air laut yang membentuk kristal garam friedel pada mortar.

\section{UCAPAN TERIMA KASIH}

Penulis terima kasih kepada PT. Semen Tonasa yang telah memberikan kesempatan untuk melakukan penelitian, pemakaian bahan dan alat di Lab Fisika PT. Semen Tonasa. 


\section{DAFTAR PUSTAKA}

Aburawy, M.M. and R. N. Swamy (2008). "Influence of salt weathering on the properties of concrete", The Arabian Journal for Science and Engineering, Vol. 33, Number 1B

JCI-TC-121A, Technical committee on the use of sea water in concrete, http://www.jci-net.or.jp/ tc121a/shushiE.html/ diakses 17 Mei 2013.

Neville, A.M. and Brooks, J.J (2010), Concrete technology, Prentice Hall, 2nd Ed

Otsuki, N., Furuya, D., Saito, T. And Tadokor, Y (2011). "Possibility of sea water as mixing water in concrete", 36 th Conference on Our world in Concrete \& Structures, Singapore.

Otsuki, N., Saito, T. and Tadokoro, Y (2012), "Possibility of sea water as mixing water in concrete", Journal of Civil Engineering and Architecture, Vol 6, No. 10 pp. 1273-1279, USA

Pruckner, F. dan Gjørv, O.E (2003), "Effect of $\mathrm{CaCl} 2$ and $\mathrm{NaCl}$ additions on concrete corrosivity", Cement and Concrete Research, 34 (2004) 1209-1217.

Rompas, R.M, Rumampuk, N.DC dan Rompas, J.R (2009). Oseanografi kimia, PT. Walaw Bengkulen, Jakarta Timur.

SNI 15-2049-2004, Semen Portland, Badan dan Standarisasi Nasional (BSN)

Wikipedia (2013). Sumber daya air, https://id.wikipedia.org, diakses Juni 2013.

Wikipedia (2013). Seawater, http://en.wikipedia.org/wiki/Seawater, diakses 26 Mei 2013

Zongjin Li (2011). Advanced concrete technology, John Wiley \& Sons, Inc, Canada. 